\title{
Influência do "Caderno de Química" em práticas de ensino em sala de aula
}

\section{The influence of the "Chemistry Textbook" in teaching practices in classroom}

\author{
Carolina José Maria ${ }^{1}$ • Joaquim Bernardino Lopes ${ }^{2}$. \\ Maria Guiomar Carneiro Tommasiello ${ }^{3}$
}

\begin{abstract}
Resumo: Este estudo teve como foco a influência do "Caderno de Química" em práticas de ensino de uma professora. A professora escolhida pode ser considerada um caso representativo da realidade vivida pelos professores das escolas públicas do Estado de São Paulo. Foram analisadas oito narrações multimodais de aulas gravadas em vídeo e, também, o Caderno de Química. Os resultados apontaram que: (a) o Caderno está presente nas práticas de ensino como autoridade externa, mas; (b) também foi demonstrado que a professora atua com alguma independência do Caderno, e (c) as concepções epistemológicas e pedagógicas do Caderno não foram identificadas nas práticas de ensino da professora.
\end{abstract}

Palavras-chave: Ensino de química. Caderno de Química. Prática de ensino. Livro didático. Ensino Médio.

\begin{abstract}
This study focused on the influence of the "Chemistry Textbook" in teacher's teaching practices. The teacher chosen can be considered as a representative case of the reality experienced by teachers generally in the public schools of the State of São Paulo. Eight multimodal narratives of lessons were videotaped and analyzed and also the Chemistry Textbook. The results showed that: (a) the Textbook is present in teaching practices as an external authority but; (b) the teacher works with some independence of Textbook, and (c) the Textbook's epistemic and pedagogical conceptions were not identified in the teacher's teaching practices.
\end{abstract}

Keywords: Chemistry teaching. Chemistry textbook. Teaching practice.Textbook. High School.

\footnotetext{
${ }^{1}$ Faculdade de Engenharia, Arquitetura e Urbanismo (FEAU), Universidade Metodista de Piracicaba (UNIMEP), Rua Visconde do Rio Branco, 45, ap. 54, Edifício Versailles, CEP 13419-110, Piracicaba, SP, Brasil. E-mail: $<$ caroljosemaria@gmail.com>

${ }^{2}$ Escola de Ciências e Tecnologias, Universidade Trás-os-Montes e Alto Douro, Vila Real, Portugal.

${ }^{3}$ Faculdade de Educação, Universidade Metodista de Piracicaba (UNIMEP), Piracicaba, SP, Brasil.
} 


\section{Introdução}

Uma formação científica de qualidade é tida como fundamental para a constituição de um indivíduo preparado para enfrentar os desafios de uma sociedade confrontada com um permanente desenvolvimento científico e tecnológico. No entanto, as pesquisas educacionais nesta área evidenciam resultados preocupantes, fato que leva os governos à proposição de iniciativas que visam minimizar os resultados negativos obtidos nas avaliações, especialmente, nas avaliações em grande escala.

Levando-se em consideração os resultados negativos obtidos nestas avaliações em grande escala (Programa Internacional de Avaliação de Estudantes - PISA, Exame Nacional do Ensino Médio - ENEM, Sistema de Avaliação do Rendimento Escolar do Estado de São Paulo - SARESP, entre outras), o estado de São Paulo, na tentativa de melhorar a qualidade do ensino da rede pública, via Secretaria de Educação (SEE), elaborou, no ano de 2007, a nova Proposta Curricular, por meio do programa "São Paulo Faz Escola" (SÃO PAULO, 2007). O objetivo desta nova proposta era melhorar o nível da educação básica na rede. Para tanto, o programa propôs várias ações, sendo a principal delas a materialização da proposta nos Cadernos do Professor e do Aluno.

A nova Proposta Curricular de Química está fundamentada na concepção de que os estudantes do nível Médio de ensino devem ser formados para que sejam capazes de se apropriar de saberes de maneira crítica e ética, por meio do desenvolvimento de competências e habilidades (SÃO PAULO, 2008). Segundo a Proposta Curricular (SÃO PAULO, 2008), o ensino da Química deve ter como objetivo que os alunos compreendam os processos químicos e suas relações e aplicações nas áreas tecnológica, ambiental e social.

Este documento defende que o ensino da Química deve ser estruturado sobre o tripé: transformações químicas, materiais e suas propriedades e modelos explicativos. Assim, o ensino de Química deve levar em consideração os Cadernos do Professor e do Aluno, material que apresenta uma função dupla nas salas de aula. Por um lado, o Caderno assume a função de auxiliar didático equiparado ao livro didático (conteúdos, atividades e estratégias de ensino); e, por outro, apresenta o planejamento das sequências de ensino que devem ser traduzidas em práticas de ensino.

O Caderno - como livro didático - é tido como importante fonte de consulta para o trabalho pedagógico do professor e, também, como instrumento para que o aluno relacione-se com a disciplina em questão, em particular, no contexto da cultura escolar brasileira (LAJOLO, 1996; LOGUERCIO; SAMRSLA; DEL PINO, 2001).

A forte associação entre o ensino e a "obrigatoriedade" da presença de um livro didático, deve-se, sobretudo, à necessidade que as grandes populações, como, por exemplo, a do Brasil, têm de tentar suprir as falhas existentes na educação (CASSIANO, 2004); isto é, os governos investem grandes quantias na produção e distribuição de livros didáticos por entenderem que um bom material, que apresente uma sequência de conteúdos e atividades, sugestões de estratégias de ensino, é capaz de compensar a ausência de professores com formação adequada.

O Caderno assume a função de planejamento das sequências de ensino, pois apresenta um conjunto de atividades estruturadas e articuladas visando alcançar objetivos determinados (MÉHEUT; PSILLOS, 2004). Em particular, o Caderno apresenta os quatro componentes básicos que devem ser levados em conta no planejamento de uma sequência: o professor, os alunos, o mundo material e o conhecimento científico (MÉHEUT; PSILLOS, 2004). Lopes et 
al. (2008) afirmam que estes componentes devem estar estruturados na dimensão epistêmica (base da concepção da sequência) e na dimensão pedagógica (aspectos relacionados ao papel do professor e as interações em sala de aula).

Para que se possa romper com visões tradicionais de ensino, é importante privilegiar a relação dos alunos com o mundo material, o que se efetiva por meio da consideração de suas concepções iniciais e de suas formas de elaboração conceitual (MÉHEUT; PSILLOS, 2004).

As sequências de ensino (sequência de assuntos e tarefas, as atividades, os textos, as sugestões didáticas) propostas pelo Caderno contemplam tais dimensões (epistêmica e pedagógica), e visam favorecer a compreensão dos conhecimentos científicos pelos alunos.

Todavia, uma questão importante que se apresenta é a distância que, em geral, existe entre o que a sequência de ensino propõe e o que, de fato, é praticado em sala de aula, uma vez que não é possível considerar a existência de uma relação direta entre as práticas de ensino desenvolvidas em sala de aula e as sequências de ensino propostas (PINTÓ; COUSO; GUTIERREZ, 2005; TRAIANOU; HAMMERSLEY, 2008).

Para que tenhamos práticas de ensino mais efetivas em sala de aula, além da disponibilidade de materiais que apresentem propostas bem embasadas e coerentes com os objetivos que se pretende alcançar, é preciso que a formação do professor seja repensada (CARVALHO; GIL-PÉREZ, 1993; ZIMMERMANN; BERTANI, 2003). Em particular, para que transformações substanciais ocorram, é preciso uma mudança das bases epistemológicas que sustentam as concepções e ações dos docentes, pois a apropriação de um novo currículo passa, necessariamente, pelo trabalho dos professores (CARVALHO; GIL-PÉREZ, 1993), e pela mudança incremental da qualidade das práticas de ensino (LOPES; VIEGAS; CRAVINO, 2010).

E uma mudança deste tipo, ou seja, uma mudança de concepções, não ocorre de forma linear e tranquila, exige transformações mais profundas, que envolvem: a construção de uma nova visão de mundo, de como se compreende o mundo e, consequentemente, como se compreende a educação, a escola, os processos de ensino e de aprendizagem de ciências, entre outros (ROEHRIG; KRUSE; KEM, 2007). E, certamente, os idealizadores da proposta, conscientes disto e conhecendo as falhas na formação da grande maioria dos professores da rede, criam formas de "traduzir" as orientações didáticas e epistemológicas subjacentes à proposta. Isto é, são elaborados materiais, entre eles, os Cadernos, para interpretar os fundamentos e expressá-los por meios de textos, exercícios, atividades etc. Assim, em tese, o trabalho do professor em sala de aula seria facilitado e estaria de acordo com os preceitos da proposta.

Embora os professores se vejam "obrigados" a utilizar o Caderno, este, por si só, não resolve os problemas de ensino e de aprendizagem em sala de aula; assim é importante considerarmos a qualidade das práticas epistêmicas e pedagógicas do professor (LOPES; BRANCO; JIMENEZ-ALEXANDRE, 2011; LOPES et al., 2010). As ações e linguagem do professor, que é o responsável pela condução da aula, influenciam as aprendizagens alcançadas pelos alunos, por intermédio das atividades propostas por ele, pelo Caderno ou por outro material qualquer. (LOPES et al., 2010).

Essas ações e linguagens podem ser condicionadas e determinadas por inúmeros fatores, que podem ser internos e/ou externos à sala de aula. Interessa-nos, neste estudo, compreender em que medida as práticas de ensino nas aulas de Química são influenciadas pelo uso do material didático (Cadernos do Aluno e do Professor). Temos de considerar que este material, embora utilizado dentro da sala de aula, chega a este espaço carregado de condicionantes externos, 
como, por exemplo, as relações existentes entre o uso dos Cadernos e as avaliações em grande escala, que possuem como objetivo avaliar o desempenho dos alunos.

Assim, este estudo pretende responder as seguintes questões: De que modo se manifesta a presença do Caderno nas aulas? Que elementos estruturais das sequências de ensino do Caderno de Química estão presentes (ou ausentes) nas práticas de ensino da professora? Quais as características das práticas de ensino da professora nas dimensões epistêmica e pedagógica tendo como referência as características do Caderno de Química nas mesmas dimensões?

\section{Metodologia da pesquisa}

\section{Participantes}

O estudo foi desenvolvido em uma escola pública estadual, que atende, em média, 800 alunos de nível Fundamental e Médio, localizada em um bairro periférico de uma cidade do interior do estado de São Paulo. As oito aulas de Química acompanhadas foram ministradas para uma turma da $2^{a}$ série do Ensino Médio (esta turma conta com duas aulas semanais da disciplina, com cinquenta minutos de duração cada), constituída por 37 alunos, grande parte residente no bairro em que a escola se localiza, com idades compreendidas entre 16 e 17 anos, e que frequentam, pela primeira vez, esta série.

A professora responsável pelas aulas é licenciada em Ciências, habilitação em química, e possui 14 anos de experiência. No ano de 2011, em que se realizou o acompanhamento das aulas, a professora possuía uma carga horária de 32 aulas semanais nesta escola, sendo vinte aulas de Química e as outras 12 divididas entre as disciplinas de Física para o Ensino Médio noturno e Ciências para as $8^{\text {as }}$ séries do período da manhã.

O caso desta professora é representativo do Ensino de Química numa escola da rede pública do Estado de São Paulo, pois sua formação inicial e continuada, as suas condições de trabalho, o acesso aos recursos didáticos, as condições físicas (salas de aula, excesso de alunos, ausência de laboratório de Ciências etc.), as orientações do governo estadual as quais deve seguir, são semelhantes às de muitos professores de Química, especificamente nas escolas públicas periféricas da cidade de Piracicaba (SP). O estudo deste caso nos dá elementos para discutir e compreender de que maneira o Caderno de Química pode influenciar as práticas de ensino da professora, tendo em conta os elementos estruturais do material, bem como as dimensões epistêmica e pedagógica presentes (ou ausentes) nas práticas de ensino em sala de aula, tendo como referência o Caderno de Química.

\section{Recolha de dados}

Os dados utilizados nestes estudos foram: gravações em áudio e vídeo das aulas, caderno de campo da pesquisadora, caderno de anotações do aluno, Cadernos do Aluno e do Professor, distribuídos pelo governo do Estado de São Paulo, e uma entrevista com a professora.

Estes dados foram organizados e estruturados em oito narrações multimodais, sendo uma de cada aula. Uma narração multimodal é uma descrição da sequência de acontecimentos (ações e linguagem de professores e alunos), desde que é proposta a tarefa (em sentido lato) até 
que se proponha outra, tentando relatar: qual o trabalho que, de fato, é realizado pelos alunos, os diálogos, os materiais usados, quais as reações, posturas, silêncios, tanto dos alunos como dos docentes (LOPES et al., 2010, 2014).

Cada narração multimodal tem imagens que nos mostram o que foi trabalhado pela professora quando esta utilizava a lousa e outros materiais, como o Caderno do Aluno e do Professor; quando apresentava um experimento ou qualquer outra atividade, e detalhes de falas, ações, posturas assumidas pela professora e pelos alunos que são fundamentais para a análise dos dados.

Para assegurar a clareza, completude e credibilidade das narrações multimodais, estas passaram por um processo de validação, realizado por um segundo investigador que não possuía conhecimento algum sobre o caso estudado, consultando os dados referidos. A participação de um pesquisador independente se fez necessária para, de acordo com Lopes et al. (2010, 2014), se validar cada narração, e não o estudo em si. No entanto, tal procedimento confere, ele próprio, maior validade ao estudo.

A Proposta Curricular do Estado de São Paulo para a disciplina de Química (SÃO PAULO, 2008), e os Cadernos do Aluno e do Professor (SÃO PAULO, 2009) também foram analisados para a discussão das questões deste estudo.

\section{Análise dos dados}

Para a realização da análise dos dados, as narrações multimodais foram importadas para o software de análise qualitativa NVivo $8^{\circledR}$. O processo de análise se deu em várias etapas. $\mathrm{Na}$ primeira etapa - análise de primeira ordem - realizamos um processo de categorização aberto, em que, a partir das próprias narrações multimodais, foram elaboradas algumas das categorias relacionadas à influência do Caderno nas práticas de ensino da professora, guiadas pelas dimensões "Formas de presença do Caderno na prática de ensino" e "Característica epistêmica da resposta escrita dos alunos às questões do Caderno".

As categorias inseridas nas dimensões "Demanda epistêmica das questões propostas pelo Caderno"; "Características epistêmicas da atividade experimental investigativa realizada na aula" e "Sugestões didáticas" emergiram não apenas da análise das narrações multimodais, mas, também, da análise do Caderno do Professor - Química, bem como do documento Proposta Curricular do Estado de São Paulo - Química. A leitura destes documentos possibilitou a identificação dos pressupostos epistemológicos e pedagógicos subjacentes às sequências de ensino apresentadas pelo Caderno, pelo que seria necessário verificar se estariam presentes ou não nas práticas de ensino da professora.

O processo de análise de cada narração multimodal nestas dimensões foi análogo ao descrito nas anteriores. Vale destacar que os trechos das narrações podem ser descritos por várias categorias, estas não são excludentes. São categorizados todos os trechos que apresentavam evidências dos aspectos de nosso interesse, especificamente, os trechos que apresentavam evidências relativas às dimensões referidas.

A categorização das narrações multimodais em todas as dimensões referidas foi feita, também, por um segundo investigador, com o intuito de validar tal categorização, obtendo-se um acordo inicial de $85 \%$. Os desacordos remanescentes foram objeto de discussão até haver acordo total entre os investigadores. 


\section{Resultados}

Na primeira parte, apresentamos os resultados obtidos sobre os modos pelos quais o Caderno está "presente" nas aulas de Química. Em um segundo momento, apresentamos os elementos estruturais da sequência de ensino que estão presentes ou não nas práticas de ensino da professora. E, finalmente, são apresentados os resultados relacionados às características epistêmicas e pedagógicas das práticas de ensino da professora, tendo como referência tais características presentes no Caderno.

\section{Modo como o Caderno está "presente" nas aulas}

Uma das maneiras de o Caderno de Química se fazer presente em aula é quando, em sua fala, a professora marca o lugar institucional ocupado por este material, ou seja, todas as vezes que o Caderno assume um lugar de autoridade em sala de aula, evidenciadas por frases como: "Então ele [Caderno] pede...”; “Ele [Caderno] fala o seguinte...”; entre outras, mostradas na categoria Cadernos do Aluno e do Professor como "autoridade", pertencente à dimensão "Formas de presença do Caderno na prática de ensino" (Quadro 1).

O Gráfico 1 mostra que o Caderno está presente, de forma explícita, em 75\% das aulas. O material foi citado pela professora para desempenhar três funções principais: (a) para determinar o que deve ser dito ou feito (autoridade); (b) para iniciar uma tarefa ou um tema por meio dos textos e atividades propostos pelo Caderno; (c) como fonte de questões para a discussão dos temas estudados.

Em todas as aulas em que o Caderno está presente, seja em maior ou menor grau, este material aparece como referência para iniciar um tema ou tarefa (Gráfico 1). O que demonstra que, em linhas gerais, os grandes temas propostos pelo Caderno de Química são contemplados em aula, independente da forma como são abordados. O Gráfico 1 também nos mostra que o uso do Caderno como fonte de questões é sempre seguido da discussão de um tema ou reali-

Gráfico 1. Funções desempenhadas pelo Caderno de Química nas práticas de ensino

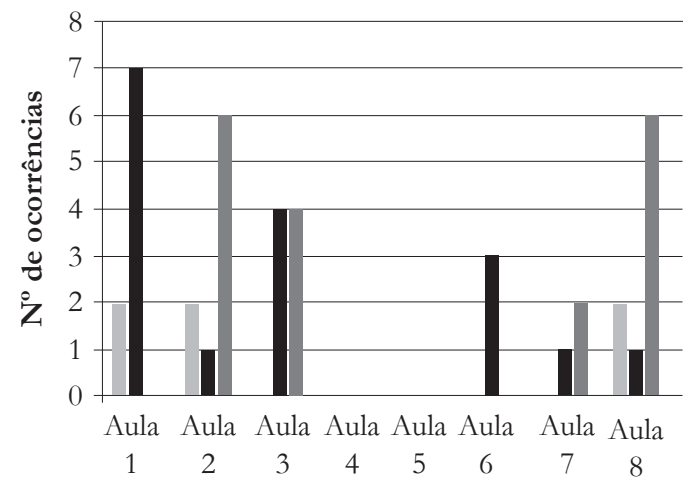

- Autoridade

- Iniciar uma tarefa ou tema

- Resolução de questões

Fonte: Elaborado pelos autores. 
zação de uma tarefa. Evidencia-se que, de modo geral, o esquema adotado pela professora em suas aulas obedece a certa sequência: discussão de um tema seguido da resolução de questões e exercícios. Nas aulas 4 e 5, o Caderno não é utilizado pela professora (Gráfico 1). Nestas aulas, a professora trabalha com pequenos textos, retirados de uma apostila pertencente a um sistema de ensino, sobre ligações químicas (ligações iônicas e covalentes). Na aula 5 , a professora propõe dois exercícios, que foram elaborados por ela mesma, sobre distribuição eletrônica e ligações químicas.

As categorias identificadas na análise das narrações multimodais relativas às "Formas de presença do Caderno na prática de ensino" estão definidas no Quadro 1. Da análise do Gráfico 2, é possível notar que, embora o Caderno esteja presente nas aulas, a professora, em alguns momentos, julga ser necessário fazer adaptações a este material. Os dois tipos de adaptações feitas (improviso e necessidade) estão relacionados à atividade experimental realizada.

Ao longo das aulas acompanhadas, pode-se observar que o discurso veiculado pelo Caderno de Química foi, muitas vezes, assumido pela professora (Gráfico 2), seja para introduzir um assunto ou explicar um fenômeno, seja para tirar dúvidas dos alunos por meio da repetição da leitura das questões. Se, por um lado, o discurso da professora se confunde com o discurso do Caderno de Química, por outro, em alguns momentos das aulas, o discurso do Caderno é totalmente ignorado pela docente, como mostrado na seção seguinte, na apresentação dos resultados obtidos a partir das sequências de ensino propostas pelo material e das práticas de ensino da professora.

Quadro 1. Categorias para "Formas de presença do Caderno na prática de ensino" e definições

\begin{tabular}{|l|l|}
\hline \multicolumn{1}{|c|}{ Categoria } & \multicolumn{1}{|c|}{ Definição } \\
\hline $\begin{array}{l}\text { Adaptação do Caderno por } \\
\text { meio do improviso }\end{array}$ & $\begin{array}{l}\text { Ao trabalhar as atividades propostas pelos Cadernos do Aluno } \\
\text { e do Professor, a professora realiza ações que não estavam } \\
\text { previstas no material. }\end{array}$ \\
\hline $\begin{array}{l}\text { Adaptação do Caderno } \\
\text { decorrente de uma necessidade }\end{array}$ & $\begin{array}{l}\text { As atividades propostas pelos Cadernos do Aluno e do } \\
\text { Professor são adaptadas devido à ausência de materiais } \\
\text { (reagentes, vidrarias, equipamentos, entre outros). }\end{array}$ \\
\hline $\begin{array}{l}\text { Cadernos do Aluno e do } \\
\text { Professor como 'autoridade' }\end{array}$ & $\begin{array}{l}\text { Na fala da professora, está marcado o lugar institucional } \\
\text { ocupado pelos Cadernos do Aluno e do Professor. }\end{array}$ \\
\hline $\begin{array}{l}\text { Coincidência entre discurso e } \\
\text { texto do Caderno }\end{array}$ & $\begin{array}{l}\text { O discurso da professora é coincidente com o texto } \\
\text { apresentado pelos Cadernos do Aluno e do Professor. }\end{array}$ \\
\hline $\begin{array}{l}\text { Insere o que não está previsto } \\
\text { no Caderno }\end{array}$ & $\begin{array}{l}\text { A professora insere, nas aulas, conteúdos, atividades, textos que } \\
\text { não estão previstos nos Cadernos do Aluno e do Professor. }\end{array}$ \\
\hline $\begin{array}{l}\text { Não trabalha o que está } \\
\text { previsto no Caderno }\end{array}$ & $\begin{array}{l}\text { A professora não trabalha alguns conteúdos e atividades } \\
\text { propostos pelos Cadernos do Aluno e do Professor. }\end{array}$ \\
\hline
\end{tabular}

Fonte: Elaborado pelos autores. 
Gráfico 2. Formas de presença do Caderno de Química nas práticas de ensino

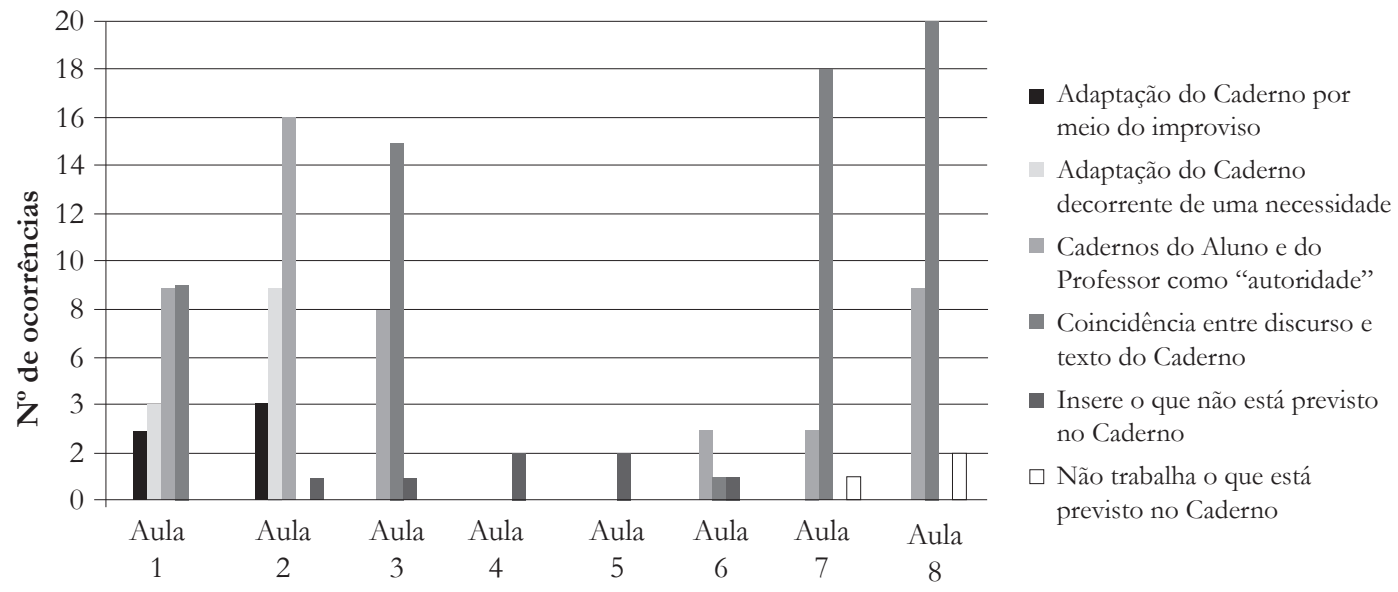

Fonte: Elaborado pelos autores.

Nas aulas 3, 4, 5 e 6 (Gráfico 2), aulas em que o tema ligações químicas foi tratado, a professora opta por trabalhar com textos retirados de outros materiais e com exercícios elaborados por ela no momento da aula, uma vez que adota uma abordagem diferente daquela proposta pelo Caderno.

Em algumas aulas (aulas 2, 7 e 8, Gráfico 2), a professora não trabalha o que é proposto pelo Caderno; tal prática é assumida quando a docente entende que os exercícios do Caderno apresentam solicitações que já foram atendidas por outra questão, e, também, quando as questões propostas exigem conteúdos que ainda não foram estudados devido à opção da professora referida acima. A professora optou por explicar a formação das ligações químicas por meio da regra do octeto, e não por meio das forças de atração e repulsão elétricas.

\section{Elementos estruturais da sequência de ensino presentes (ou ausentes) nas práticas de ensino}

Nesta seção apresentamos os resultados obtidos a partir da análise do Caderno e das narrações multimodais relativos aos elementos estruturais, respectivamente, das sequências de ensino propostas no Caderno (Quadro 2), e das sequências de ensino da professora (Quadro 3).

Embora as sequências de ensino propostas pelo Caderno tenham sido tomadas como referência para o desenvolvimento das aulas pela professora, os respectivos elementos estruturais não são completamente coincidentes.

Comparando as sequências de ensino propostas no Caderno e as sequências de ensino praticadas pela professora (quadros 2 e 3, respectivamente), verifica-se que a presença do Caderno de Química em sala de aula não é garantia de que seu uso se dá de forma completa, no sentido de definir o que deve ser trabalhado e como deve ser trabalhado. 
Por exemplo, o Caderno propõe uma atividade experimental que tem como objetivo a compreensão de que o modelo atômico de Rutherford-Bohr pode ser utilizado para explicar o comportamento da matéria; para tanto, sugere o estudo dos principais modelos atômicos (Dalton, Thomson, Rutherford e Bohr), com a intenção de que os alunos compreendam a limitação de alguns e as possibilidades de outros. Contudo, a professora inicia a atividade retomando o modelo atômico de Dalton, porém não faz nenhuma relação com a atividade que será realizada, e, ao explicar os fenômenos observados, utiliza reações de ionização e dissociação iônica.

Quadro 2. Elementos estruturais das sequências de ensino propostas pelo Caderno de Química

Sequência de ensino 1 (Situação de Aprendizagem 1 - Explicando o comportamento de materiais: modelos sobre a estrutura da matéria)

Atividade 1.1 - O modelo de Rutherford-Bohr para explicar o comportamento da matéria

\begin{tabular}{|c|c|}
\hline $\begin{array}{r}\text { Tarefas } \\
\text { Sugestões didáticas } \\
\text { Competências e habilidades }\end{array}$ & $\begin{array}{l}\text { Natureza elétrica da matéria - condutibilidade elétrica dos materiais, } \\
\text { isolantes e condutores. } \\
\text { Realização do experimento: Condutibilidade elétrica - um critério } \\
\text { para classificar os materiais } \\
\text { Levantamento dos conhecimentos prévios; leitura de textos; } \\
\text { experimentação para coleta de dados; organização dos dados } \\
\text { em tabelas; proposição de questões para análise dos resultados; } \\
\text { elaboração de conclusões; discussão geral. } \\
\text { Classificação e estabelecimento de critérios; controle de variáveis; } \\
\text { elaboração de modelo explicativo. }\end{array}$ \\
\hline \multicolumn{2}{|c|}{ Atividade 1.2 - Do átomo de Dalton ao átomo de Rutherford-Bohr } \\
\hline Competências e habilidades & $\begin{array}{l}\text { Modelos explicativos; Ideias sobre o átomo: Thomson, Rutherford e } \\
\text { Bohr; Radioatividade natural. } \\
\text { Retomada das ideias desenvolvidas na atividade anterior } \\
\text { (experimento e questões) para evidenciar a necessidade de se } \\
\text { construírem outras ideias sobre a constituição da matéria (modelos } \\
\text { atômicos) } \\
\text { Identificação dos conhecimentos prévios; leitura de textos; questões } \\
\text { propostas; discussão geral; introdução da História da Ciência no } \\
\text { processo de elaboração do conhecimento; elaboração de texto } \\
\text { síntese. } \\
\text { Compreender as limitações das ideias de Dalton e a necessidade } \\
\text { de modificá-las; compreender os experimentos de Rutherford e a } \\
\text { interpretação dos fatos observados que levaram ao modelo de átomo } \\
\text { nuclear; aplicar as ideias de Rutherford para explicar fenômenos } \\
\text { químicos. }\end{array}$ \\
\hline
\end{tabular}


Quadro 2. continuação

\begin{tabular}{|c|c|}
\hline \multicolumn{2}{|c|}{$\begin{array}{l}\text { Sequência de ensino } 1 \text { (Situação de Aprendizagem } 1 \text { - Explicando o comportamento } \\
\text { de materiais: modelos sobre a estrutura da matéria) }\end{array}$} \\
\hline \multicolumn{2}{|r|}{ Atividade 1.3 - A tabela periódica revisitada } \\
\hline $\begin{array}{r}\text { Competências e habilidades } \\
\text { Sequência de ensino } 2 \\
\text { (Situação de Aprendizagem) }\end{array}$ & $\begin{array}{l}\text { Tabela periódica - número atômico, um novo critério na organização } \\
\text { dos elementos; Propriedades e estrutura dos átomos. } \\
\text { Estudo da estrutura e organização da tabela periódica. } \\
\text { Levantamento dos conhecimentos prévios; leitura de textos; } \\
\text { discussão geral; questões propostas; trabalho em grupo. } \\
\text { Classificar os elementos químicos em diferentes grupos; reconhecer } \\
\text { a tabela periódica como uma forma de sistematização do } \\
\text { conhecimento químico; prever propriedades dos elementos e seus } \\
\text { compostos em função da posição que ocupam na tabela. }\end{array}$ \\
\hline \multicolumn{2}{|c|}{$\begin{array}{l}\text { Sequência de ensino } 2 \text { (Situação de Aprendizagem } 2 \text { - Explicando o comportamento } \\
\text { de materiais: as ligações entre átomos, íons e moléculas) }\end{array}$} \\
\hline \multicolumn{2}{|c|}{$\begin{array}{c}\text { Atividade } 2.1 \text { - As ideias sobre a estrutura da matéria para explicar a existência das } \\
\text { substâncias: as ligações químicas }\end{array}$} \\
\hline $\begin{array}{r}\text { Sugestões didáticas } \\
\text { Competências e habilidades }\end{array}$ & $\begin{array}{l}\text { Forças de atração e de repulsão elétrica; ligação química. } \\
\text { Estudo da formação das ligações - forças de atração e repulsão } \\
\text { elétricas. } \\
\text { Aulas expositivas dialogadas; trabalho em grupo. } \\
\text { Interpretar a ligação química em termos de atrações e repulsões } \\
\text { entre elétrons e núcleos, relacionando-as às propriedades das } \\
\text { substâncias de maneira a ampliar o entendimento do mundo físico; } \\
\text { reconhecer a ideia de ligação química como um modelo explicativo. }\end{array}$ \\
\hline
\end{tabular}

Fonte: Elaborado pelos autores.

Ou seja, em sua ação, a professora assume a atividade prática em si, mas não os fundamentos propostos pelo Caderno que explicam os resultados.

Em relação à sequência de temas assumida pela professora nas aulas, esta difere da sequência proposta pelo Caderno. A professora faz uma inversão da sequência proposta pelo material ao ensinar o tema ligações químicas antes do tema tabela periódica. Não somente a sequência de temas é alterada, mais uma vez, assim como aconteceu na primeira atividade, mas a forma de abordagem deles também.

Para o ensino do tema ligações químicas, a professora não utiliza o conteúdo (textos e questões) apresentado pelo Caderno de Química, assume a regra de octeto para explicar a formação das ligações iônicas e covalentes, apoiando-se em pequenos textos retirados de outro material e em exercícios por ela elaborados. 
Quadro 3. Elementos estruturais das sequências de ensino da professora em sala de aula

\begin{tabular}{|c|c|}
\hline \multicolumn{2}{|r|}{ Sequência de ensino 1 - Aulas 1,2 e 3} \\
\hline $\begin{array}{r}\text { Tarefas } \\
\text { Opções didáticas } \\
\text { Competências trabalhadas }\end{array}$ & $\begin{array}{l}\text { Condutibilidade elétrica dos materiais - isolantes e condutores; } \\
\text { reações de ionização e dissociação iônica (ênfase no papel da água } \\
\text { como responsável pela "quebra" das ligações entre os elementos, } \\
\text { formando os íons responsáveis pela condução de corrente elétrica). } \\
\text { Realização do experimento: Condutibilidade elétrica; resolução das } \\
\text { questões propostas pelo Caderno. } \\
\text { Experimento demonstrativo para coleta de dados; organização dos } \\
\text { dados em tabelas; resolução de questões para análise dos resultados; } \\
\text { elaboração de conclusões. } \\
\text { Classificação e estabelecimento de critérios. }\end{array}$ \\
\hline \multicolumn{2}{|r|}{ Sequência de ensino $2-$ Aulas $3,4,5$ e 6} \\
\hline $\begin{array}{r}\text { Conteúdos } \\
\text { Tarefas } \\
\text { Opções didáticas }\end{array}$ & $\begin{array}{l}\text { Distribuição eletrônica; ligações químicas - iônicas e covalentes } \\
\text { (regra do octeto). } \\
\text { Estudo da formação das ligações químicas. } \\
\text { Explicação baseada na ideia de estabilidade do átomo - regra do } \\
\text { octeto; utilização de pequenos textos sobre o tema; exercícios; } \\
\text { correção dos exercícios. } \\
\text { Execução de procedimentos; uso de regras. }\end{array}$ \\
\hline \multicolumn{2}{|r|}{ Sequência de ensino 3 - Aulas 6,7 e 8} \\
\hline Competências trabalhadas & $\begin{array}{l}\text { Tabela periódica: breve histórico sobre a organização dos elementos; } \\
\text { informações contidas na tabela. } \\
\text { Estudo da tabela periódica: histórico; relação entre a organização } \\
\text { dos elementos químicos e o número de elétrons na camada de } \\
\text { valência; nome das famílias (grupos) da tabela. } \\
\text { Resolução das questões (tabela periódica) propostas pelo Caderno; } \\
\text { utilização de pequenos textos, resolução de questões propostas pelo } \\
\text { Caderno (pertencentes a outro tema). } \\
\text { Classificar os elementos químicos em diferentes grupos; uso de } \\
\text { regras. }\end{array}$ \\
\hline
\end{tabular}

Fonte: Elaborado pelos autores.

\section{Características das práticas de ensino nas dimensões epistêmica e pedagógica, tendo como referência o Caderno}

Nesta última seção, são apresentados os resultados relacionados às características epistêmicas e pedagógicas presentes nas práticas de ensino, tendo como referência estas mesmas características no Caderno de Química. 
O Quadro 4 apresenta as categorias identificadas na análise e as suas definições que emergiram da análise das questões propostas pelo Caderno que foram trabalhadas pela professora ao longo das aulas acompanhadas. E tendo em conta as demandas epistêmicas destas questões, foi possível verificar se estas foram atendidas por meio da análise do registro escrito dos alunos na dimensão "Características epistêmicas da resposta escrita dos alunos às questões do Caderno” (Quadro 5). Nesta dimensão, foram destacados três tipos de respostas: as que atendem à demanda epistêmica da questão, as que atendem parcialmente, e as que não atendem.

Verifica-se que a professora pouco explora as exigências epistêmicas da questão. $\mathrm{O}$ Gráfico 3 mostra que a soma dos valores que representam as respostas que não atendem e que atendem parcialmente às solicitações epistêmicas das questões é maior do que a porcentagem que representa as respostas que atendem a tais demandas - o que evidencia que os objetivos pretendidos pelo Caderno por meio da resolução das questões não foram completamente atingidos. Por outro lado, é importante destacar que as respostas escritas dos alunos que atendem à demanda epistêmica posta pelo Caderno de Química são questões que exigem respostas menos elaboradas, como, por exemplo, que solicitam apenas uma classificação de materiais ou localização de elementos químicos, ou, ainda, que enfatizam a repetição de procedimentos (seguir regras).

Ainda considerando a dimensão epistêmica da prática de ensino da professora, tendo em conta a mesma dimensão no Caderno, apresentamos, no Quadro 6, as categorias relacionadas à atividade experimental e, no Gráfico 4, o número de ocorrências destas categorias distribuído ao longo aulas.

O número de ocorrências destas categorias está distribuído ao longo das quatro primeiras aulas (Gráfico 4), pois as discussões acerca da atividade experimental se estenderam ao longo destas.

A dimensão apresentada no Quadro 6 apresenta catorze categorias, das quais apenas seis manifestam-se nas práticas de ensino da professora (Quadro 6 e Gráfico 4). As características epistêmicas principais, ou seja, aquelas que poderiam favorecer a construção do conhecimento pelo aluno não são contempladas na prática; uma das evidências de tal colocação é o fato de a docente antecipar os resultados dos testes, negando, assim, aos alunos, a oportunidade de refletirem e expressarem as suas ideias sobre o fenômeno que será demonstrado.

Observamos, também, pelo Gráfico 4, que as questões complementares (em geral, questões de classificação e organização dos dados obtidos), relacionadas à atividade experimental, têm grande destaque durante a correção com a turma toda, enquanto as questões centrais, aquelas que de fato levariam a compreensão do fenômeno, não são exploradas pela professora.

Outro ponto que chama a atenção no Gráfico 4, e que, mais uma vez, reforça a ideia de que a proposta apresentada pelo Caderno é apenas parcialmente assumida pela professora, é a utilização de um modelo explicativo alternativo, isto é, em suas explicações utiliza um modelo explicativo diferente daquele que é sugerido pelo Caderno de Química.

Tratando-se da dimensão pedagógica subjacente à ação da professora, são apresentadas, no Quadro 7, as categorias identificadas a partir da análise dos dados, tendo como referência esta mesma dimensão presente no Caderno de Química.

Como é possível observar no Gráfico 5, apenas duas categorias são contempladas nas práticas da professora, em apenas uma aula e uma única vez. Isto é, poucas oportunidades de expressarem e trabalharem suas próprias concepções são oferecidas aos alunos. 
Quadro 4. Categorias para “Demanda epistêmica das questões propostas pelo Caderno”, definições e exemplos

\begin{tabular}{|c|c|c|}
\hline Categoria & Definição & Trecho da Narração Multimodal \\
\hline Classificação & $\begin{array}{l}\text { A questão apresentada pelo Caderno } \\
\text { do Aluno e do Professor ou elaborada } \\
\text { pela professora solicita a classificação } \\
\text { de materiais, de elementos químicos. }\end{array}$ & $\begin{array}{l}\text { P: [Quinto] Considerando as observações } \\
\text { da tabela reagrupe os materiais testados } \\
\text { de acordo com os estados em que eles são } \\
\text { considerados condutores de corrente, ou seja, } \\
\text { sólido, líquido, dissolvido ou fundido. }\end{array}$ \\
\hline $\begin{array}{l}\text { Identificação } \\
\text { das condições } \\
\text { empíricas }\end{array}$ & $\begin{array}{l}\text { A questão do Caderno do Aluno e do } \\
\text { Professor ou elaborada pela professora } \\
\text { solicita a identificação das condições } \\
\text { em que um fenômeno ocorre. }\end{array}$ & $\begin{array}{l}\text { P: Entre os materiais testados há algum que } \\
\text { possa ser classificado ao mesmo tempo como } \\
\text { condutor e isolante? }\end{array}$ \\
\hline Conclusão & $\begin{array}{l}\text { A questão apresentada pelo Caderno } \\
\text { do Aluno e do Professor ou elaborada } \\
\text { pela professora solicita que, a partir } \\
\text { dos dados ou do próprio enunciado, o } \\
\text { aluno elabore uma conclusão. }\end{array}$ & $\begin{array}{l}\text { P: [Sexta]: Analisando os dados coletados } \\
\text { pode-se perceber que alguns materiais no } \\
\text { estado sólido, como a madeira, são isolantes } \\
\text { e outros como o ferro e o alumínio são } \\
\text { condutores. Considerando a corrente elétrica } \\
\text { como movimento de cargas que suposição é } \\
\text { possível fazer sobre a natureza e a liberdade } \\
\text { do movimento das partículas que constituem } \\
\text { os materiais condutores? }\end{array}$ \\
\hline $\begin{array}{l}\text { Conversão } \\
\text { entre registros } \\
\text { semióticos }\end{array}$ & $\begin{array}{l}\text { A questão do Caderno do Aluno e do } \\
\text { Professor ou elaborada pela professora } \\
\text { solicita que o aluno faça conversões } \\
\text { entre registros semióticos. }\end{array}$ & $\begin{array}{l}\text { P: É, represente a água por meio de sua } \\
\text { fórmula química. }\end{array}$ \\
\hline Explicação & $\begin{array}{l}\text { A questão apresentada pelo Caderno } \\
\text { do Aluno e do Professor ou elaborada } \\
\text { pela professora solicita a explicação de } \\
\text { um fenômeno. }\end{array}$ & $\begin{array}{l}\text { P: [Na quarta ele fala o seguinte] Entre os } \\
\text { materiais testados há algum que possa ser } \\
\text { classificado ao mesmo tempo como um } \\
\text { condutor e como um isolante? Explique. }\end{array}$ \\
\hline Uso de modelo & $\begin{array}{l}\text { A questão do Caderno do Aluno e do } \\
\text { Professor ou elaborada pela professora } \\
\text { solicita a utilização ou elaboração de } \\
\text { um modelo. }\end{array}$ & $\begin{array}{l}\text { P: [Terceira] [terceira questão do Caderno } \\
\text { do Professor]: Faça um resumo de como os } \\
\text { elétrons devem ser distribuídos nos níveis de } \\
\text { energia conforme o modelo de Bohr. }\end{array}$ \\
\hline $\begin{array}{l}\text { Uso de } \\
\text { representações }\end{array}$ & $\begin{array}{l}\text { A questão do Caderno do Aluno e do } \\
\text { Professor ou elaborada pela professora } \\
\text { solicita a utilização ou elaboração de } \\
\text { diferentes tipos de representações. }\end{array}$ & $\begin{array}{l}\text { P: Cinco [quinta questão do Caderno do } \\
\text { Professor]: Para cada um dos elementos do } \\
\text { grupo escolhido distribua os elétrons nos } \\
\text { níveis de energia dos átomos dos elementos. }\end{array}$ \\
\hline $\begin{array}{l}\text { Estabelecer } \\
\text { relações }\end{array}$ & $\begin{array}{l}\text { A questão do Caderno do Aluno e do } \\
\text { Professor ou elaborada pela professora } \\
\text { solicita o uso/estabelecimento de } \\
\text { relações entre conceitos, variáveis. }\end{array}$ & $\begin{array}{l}\text { P: [Terceira]: Os materiais considerados } \\
\text { condutores conduzem corrente elétrica com } \\
\text { a mesma intensidade? }\end{array}$ \\
\hline
\end{tabular}

Fonte: Elaborado pelos autores. 
Quadro 5. Categorias para "Característica epistêmica da resposta escrita dos alunos às questões do Caderno", definições e exemplos

\begin{tabular}{|c|c|c|}
\hline Categoria & Definição & Trecho da Narração Multimodal \\
\hline Não atende & $\begin{array}{l}\text { A resposta escrita do aluno } \\
\text { não atende à demanda } \\
\text { epistêmica da questão } \\
\text { proposta pelos Cadernos } \\
\text { do Aluno e do Professor. }\end{array}$ & 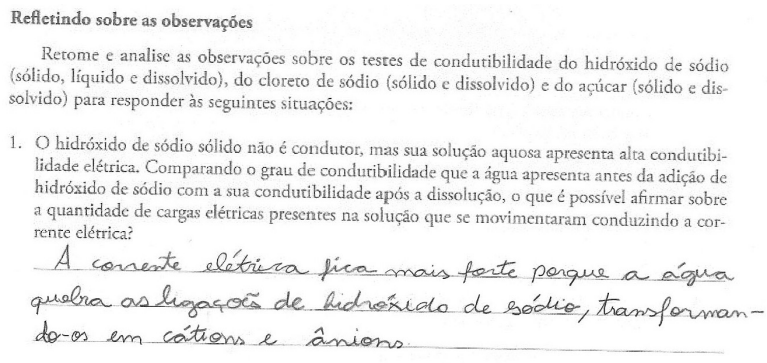 \\
\hline Atende & $\begin{array}{l}\text { A resposta escrita do } \\
\text { aluno atende à demanda } \\
\text { epistêmica da questão } \\
\text { proposta pelos Cadernos } \\
\text { do Aluno e do Professor. }\end{array}$ & 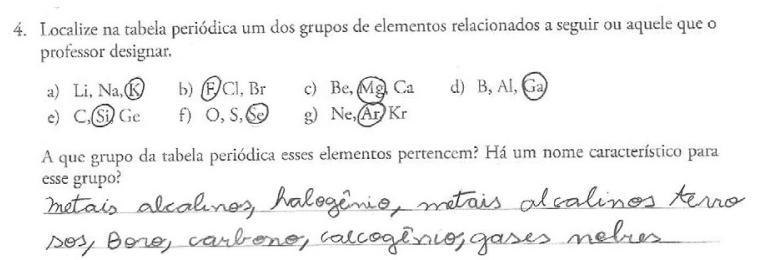 \\
\hline $\begin{array}{l}\text { Atende } \\
\text { parcialmente }\end{array}$ & $\begin{array}{l}\text { A resposta escrita do } \\
\text { aluno atende parcialmente } \\
\text { à demanda epistêmica da } \\
\text { questão proposta pelos } \\
\text { Cadernos do Aluno e do } \\
\text { Professor. }\end{array}$ & 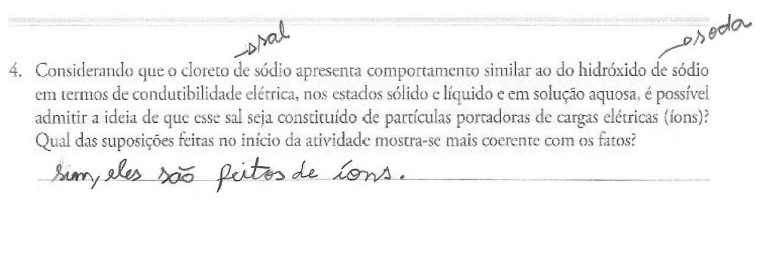 \\
\hline
\end{tabular}

Fonte: Elaborado pelos autores.

Gráfico 3. Características epistêmicas da resposta escrita dos alunos

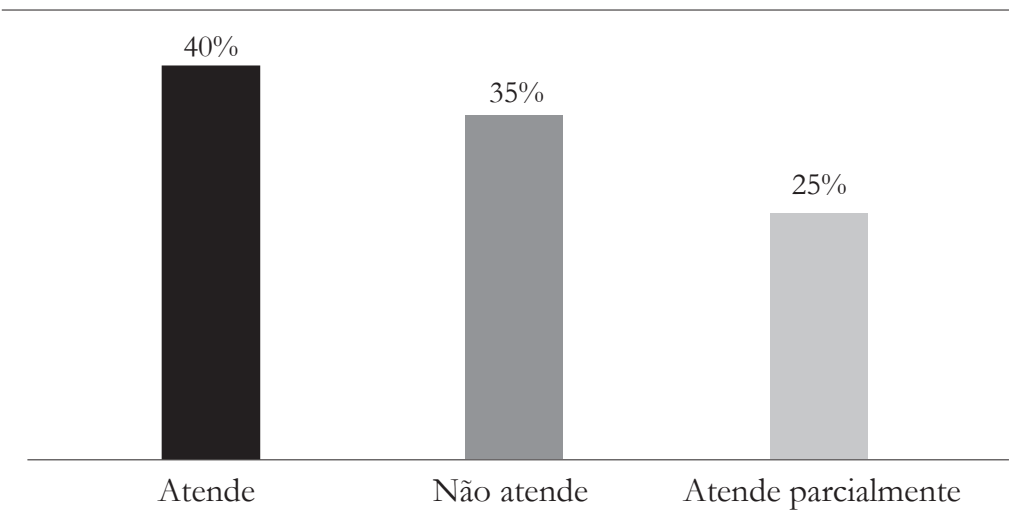

Fonte: Elaborado pelos autores. 
Quadro 6. Categorias para "Características epistêmicas da atividade experimental investigativa realizada na aula" e definições

\begin{tabular}{|c|c|}
\hline Categoria & Definição \\
\hline Confronto & $\begin{array}{l}\text { O modelo explicativo é confrontado com os dados. Os dados são usados } \\
\text { para avaliar o modelo. }\end{array}$ \\
\hline Construção conjunta & $\begin{array}{l}\text { O modelo explicativo é construído por professor e alunos de forma } \\
\text { conjunta. }\end{array}$ \\
\hline $\begin{array}{l}\text { Enfase nas questões } \\
\text { centrais }\end{array}$ & $\begin{array}{l}\text { Na discussão com o grupo todo, para a resolução do problema (correção } \\
\text { de questões propostas pelo Caderno), o professor enfatiza a elaboração } \\
\text { das respostas às questões centrais do problema. }\end{array}$ \\
\hline $\begin{array}{l}\text { Enfase nas questões } \\
\text { complementares }\end{array}$ & $\begin{array}{l}\text { Na discussão com o grupo todo, para resolução do problema (correção de } \\
\text { questões propostas pelo Caderno), o professor enfatiza a elaboração das } \\
\text { respostas às questões complementares (em geral, questões que contribuem } \\
\text { para a organização dos dados). }\end{array}$ \\
\hline $\begin{array}{l}\text { Levantamento de } \\
\text { hipóteses }\end{array}$ & $\begin{array}{l}\text { Os alunos dispõem de tempo para levantar hipóteses acerca do } \\
\text { experimento que será realizado. }\end{array}$ \\
\hline $\begin{array}{l}\text { Modelo explicativo } \\
\text { alternativo }\end{array}$ & $\begin{array}{l}\text { Para a discussão das questões que auxiliam a resolução do problema } \\
\text { proposto, o professor utiliza um modelo explicativo alternativo, diferente } \\
\text { do que é sugerido pelo Caderno. }\end{array}$ \\
\hline $\begin{array}{l}\text { Modelo explicativo } \\
\text { proposto }\end{array}$ & $\begin{array}{l}\text { Para a discussão das questões que auxiliam a resolução do problema } \\
\text { proposto, o professor utiliza o modelo explicativo sugerido pelo Caderno. }\end{array}$ \\
\hline Observação orientada & $\begin{array}{l}\text { Os alunos são orientados a observar os aspectos mais relevantes do } \\
\text { experimento. }\end{array}$ \\
\hline Problema & $\begin{array}{l}\text { A atividade é colocada na forma de um problema, por meio de questões } \\
\text { ou situações, para que os alunos elaborem soluções. }\end{array}$ \\
\hline Progressivo & $\begin{array}{l}\text { São incorporados, ao modelo explicativo, aspectos dos dados e dos } \\
\text { fenômenos, ou seja, o modelo vai sendo aperfeiçoado. }\end{array}$ \\
\hline Registro dos dados & $\begin{array}{l}\text { Os alunos são orientados a registrar os dados obtidos no experimento, de } \\
\text { forma clara e organizada, para posterior leitura e análise. }\end{array}$ \\
\hline Resposta auxiliada & $\begin{array}{l}\text { O professor, frente às dúvidas dos alunos, auxilia-os na elaboração de uma } \\
\text { resposta para o problema proposto. }\end{array}$ \\
\hline Resposta "fornecida" & O professor apresenta a resposta frente ao silêncio dos alunos. \\
\hline $\begin{array}{l}\text { Resposta elaborada } \\
\text { pelo aluno }\end{array}$ & $\begin{array}{l}\text { Os alunos dispõem de tempo para elaborar suas respostas de forma } \\
\text { autônoma. }\end{array}$ \\
\hline
\end{tabular}

Fonte: Elaborado pelos autores. 
Gráfico 4. Características epistêmicas da atividade experimental investigativa

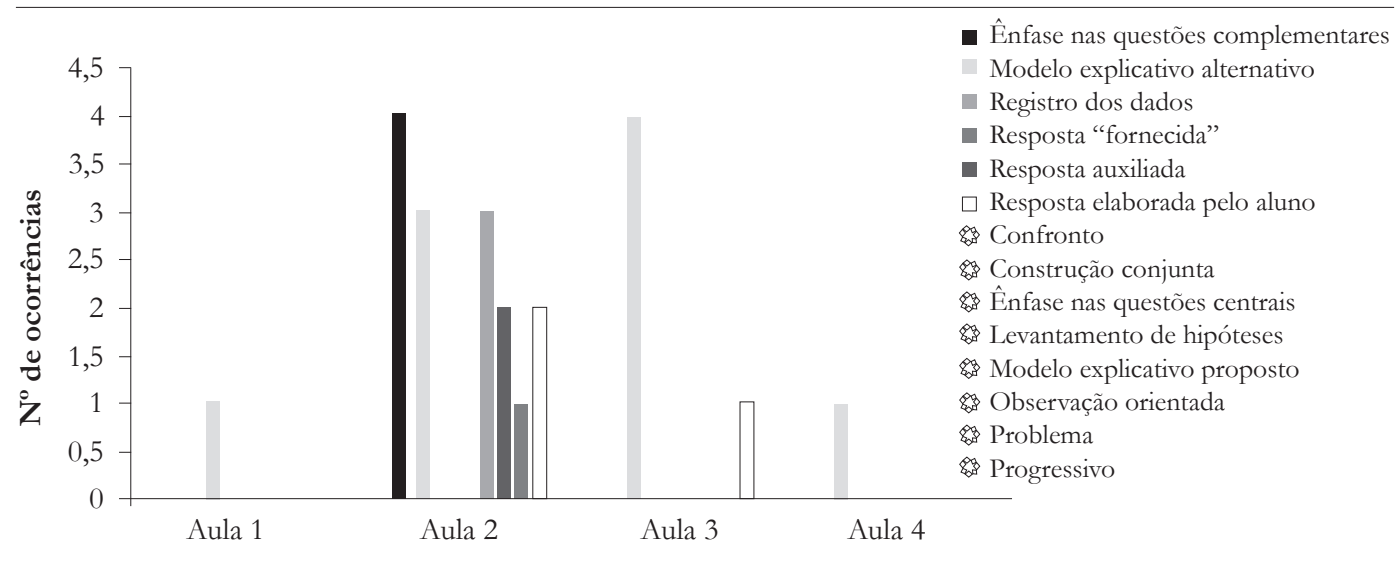

Fonte: Elaborado pelos autores.

Quadro 7. Categorias para "Sugestões didáticas" e definições

\begin{tabular}{|l|l|}
\hline \multicolumn{1}{|c|}{ Categoria } & \multicolumn{1}{c|}{ Definição } \\
\hline Trabalhadas pelo aluno & $\begin{array}{l}\text { O professor solicita que o aluno discuta e aprofunde suas ideias } \\
\text { prévias. }\end{array}$ \\
\hline Identificação & $\begin{array}{l}\text { São utilizados questionamentos e situações para identificar as ideias } \\
\text { prévias dos alunos. }\end{array}$ \\
\hline Trabalhadas pelo professor & $\begin{array}{l}\text { As ideias prévias dos alunos são discutidas e aprofundadas pelo } \\
\text { professor. }\end{array}$ \\
\hline Texto síntese & $\begin{array}{l}\text { É solicitada, aos alunos, a elaboração de textos que sintetizem as } \\
\text { ideias desenvolvidas durante uma atividade. }\end{array}$ \\
\hline
\end{tabular}

Fonte: Elaborado pelos autores.

Em geral, a professora faz a resolução das questões juntamente com os alunos, ação que evidencia a ausência de situações que possibilitem, aos alunos, a oportunidade de refletirem sobre os problemas apresentados pelas questões. E, também, esta prática leva ao entendimento de que a docente supõe que, a partir da discussão, da correção das questões com toda a turma, os alunos elaboram as respostas escritas desejadas, uma vez que esta não se assegura de que os alunos a realizaram de maneira correta. 


\section{Discussão}

Gráfico 5. Sugestões didáticas

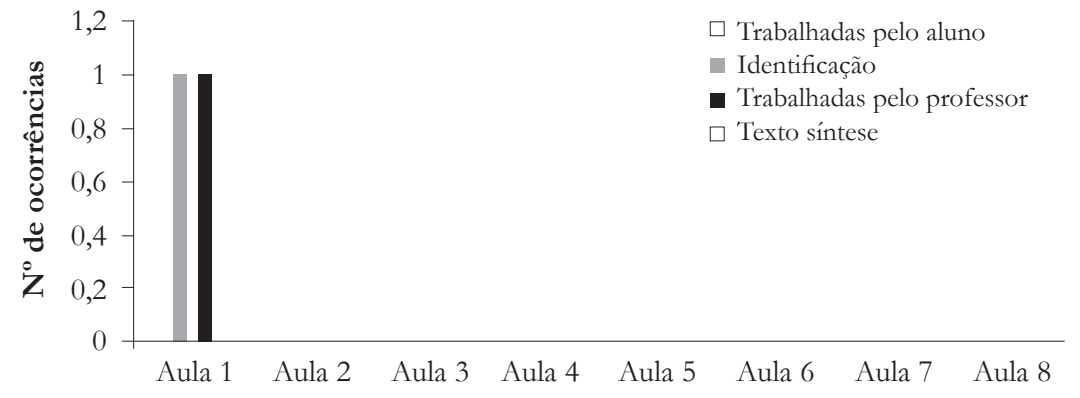

Fonte: Elaborado pelos autores.

Os resultados obtidos por este estudo indicam, em uma primeira análise, que o material elaborado pela Secretaria da Educação de São Paulo - os Cadernos do Professor e do Aluno são rigorosamente seguidos pela professora. Porém, uma análise mais cuidadosa das aulas e do próprio Caderno indica que a natureza da proposta não é comtemplada durante as atividades realizadas em sala de aula. Ou seja, o Caderno está presente em sala de aula, mas apenas em alguns aspectos sua influência é refletida nas práticas de ensino da professora.

A docente em estudo parece compreender o Caderno não como um instrumento auxiliar em sala de aula, mas, sim, como uma autoridade (FREITAG; COSTA; MOTTA, 1997). Todavia, a professora não usa o Caderno em sua completude em sala de aula, tanto em termos didáticos como epistemológicos, como os resultados evidenciam.

A professora, ao trabalhar alguns conteúdos, optou por uma abordagem diferente daquela proposta pelo Caderno, como, por exemplo, no ensino do conceito ligações químicas. Para a professora, a utilização da ideia da estabilidade dos gases nobres e da regra de octeto para justificar a formação das ligações químicas é a forma mais adequada para o ensino do tema, embora o Caderno de Química deixe explícito o contrário, reforçando o que muitos estudos já afirmam há muito tempo, ou seja, o uso da regra de octeto é um procedimento útil, mas acaba por se transformar num ritual, num conjunto de regras (MORTIMER; MOL; DUARTE, 1994).

Em relação aos elementos das sequências de ensino que são ou não incorporados à prática da professora, a análise dos dados nos permite afirmar que as práticas de ensino em sala de aula são orientadas, sobretudo, pelos temas principais e pelas atividades propostas pelo Caderno, o que não significa dizer que os objetivos de aprendizagem, as competências e habilidades a serem desenvolvidas pelos alunos (segundo orientações do Caderno) são comtempladas. Ao contrário, na maioria das vezes, estes objetivos não são considerados pela professora.

O Caderno assume, como fio condutor das sequências de ensino, o trabalho com modelos, porém este tipo de ensino não é assumido pela professora. O uso de modelos é es- 
sencial no ensino e na aprendizagem da Química para que os conceitos não fiquem reduzidos à simples descrição das propriedades e transformações macroscópicas. No entanto, é evidente que o trabalho com modelos não é uma tarefa fácil, uma vez que os alunos, com o auxílio do professor, devem apropriar-se de elementos que os levem da observação ao entendimento e formulação de modelos explicativos (PEREIRA JUNIOR; AZEVEDO, 2011), e vice-versa.

Pode-se inferir, da análise dos resultados, que as dimensões epistêmica e pedagógica presentes nas sequências de ensino propostas pelo Caderno de Química não são amplamente apropriadas pela professora. O que se observa são aspectos pontuais do Caderno presentes nas práticas de ensino.

Um ponto que chama atenção no Caderno do professor: química é a orientação referente à atividade experimental. No Caderno está explícita a concepção de que a atividade experimental deve apresentar caraterística investigativa, uma vez que este tipo de atividade pode favorecer o desenvolvimento de competências e habilidades fundamentais para o saber científico, como, por exemplo, a formulação de hipóteses e explicações, o confronto entre os dados, entre outras (HOFSTEIN, 2004; HOFSTEIN; MAMLOK-NAAMAN, 2007). Contudo, em sua prática, a professora não cria oportunidades que favoreçam o desenvolvimento de tais competências e habilidades.

Embora a professora, aparentemente, trabalhe com o material fornecido pelo governo estadual, entendemos que a sua prática em sala de aula reflete os seus saberes (PREDEBON; DEL PINO, 2009), ou seja, está baseada em suas concepções que se constituíram ao longo de sua formação e ação profissional (TARDIF, 2002). As práticas de sala de aula são diretamente influenciadas pelas crenças da professora (ROEHRIG; KRUSE; KEM, 2007), fato que a leva a fazer opções ao longo do seu trabalho, apesar da presença do Caderno de Química. Seria importante, e na linha de estudos que mostram a importância de uma mudança incremental das práticas de ensino baseadas na análise das práticas anteriores (LOPES; VIEGAS; CRAVINO, 2010), considerar um acompanhamento e formação dos docentes que aplicam a proposta curricular do programa "São Paulo faz Escola".

\section{Conclusões}

A presença do material didático (livros e Cadernos) é tão forte no contexto brasileiro que este parece "ganhar vida" nas falas do professor, ou seja, parece tratar-se de uma pessoa que está em sala de aula para apresentar o que deve ser feito. Por sua vez, os alunos estão tão acostumados com a presença desta "autoridade" em sala de aula que sequer fazem qualquer questionamento acerca do que está escrito no material. Este estudo confirmou esta presença nas práticas de ensino como referência da autoridade externa.

Todavia, este estudo mostrou que a professora tem margem de liberdade e usou-a alterando a sequência de ensino em diversos aspectos: sequência dos conteúdos, alteração de algumas atividades e afastamento relativamente à abordagem de alguns conceitos.

Mostrou ainda que as concepções epistêmicas e pedagógicas da proposta do Caderno não estão presentes nas práticas de ensino, reconhecendo-se apenas alguns aspectos circunstanciais da proposta. 
Toda ação refletida e realizada no sentido de contribuir para a melhoria do ensino nas escolas públicas do estado de São Paulo deve ser apoiada. No entanto, este estudo mostrou que os fundamentos da Proposta Curricular, materializados no Caderno de Química, por si só, não são capazes de transformar as práticas de ensino e, consequentemente, as aprendizagens dos alunos. Será necessário, pois, se considerarem ações de acompanhamento para a melhoria progressiva das práticas de ensino.

\begin{abstract}
Agradecimentos
Agradeço à Coordenação de Aperfeiçoamento de Pessoal de Nível Superior (CAPES) pela bolsa sanduíche (PDSE Processo no 2528/12-6), período de estudos realizado na Universidade Trás-os-Montes e Alto Douro, em Vila Real, Portugal, sob a orientação do Professor Joaquim Bernardino Lopes.
\end{abstract}

\title{
Referências
}

CARVALHO, A. M. P.; GIL-PÉREZ, D. Formação de professores de ciências: tendências e inovações. São Paulo: Cortez, 1993.

CASSIANO, C. C. F. Aspectos políticos e econômicos da circulação do livro didático de História e suas implicações curriculares. História, São Paulo, v. 23, n. 1-2, p. 33-48, 2004. Disponível em: < http://www.scielo.br/pdf/his/v23n1-2/a03v2312.pdf > . Acesso em: 28 jan. 2015.

FREITAG, B.; COSTA, W. F.; MOTTA, V. R. O livro didático em questão. 3. ed. São Paulo: Cortez, 1997.

HOFSTEIN, A. The laboratory in chemistry education: thirty years of experience with developments, implementation and research. Chemistry Education Research and Practice, Cambridge, v. 5, n. 3, p. 247-264, 2004.

HOFSTEIN, A.; MAMLOK-NAAMAN, R. The laboratory in science education: the state of the art. Chemistry Education Research and Practice, Cambridge, v. 8, n. 2, p. 105$107,2007$.

LAJOLO, M. P. Livro didático: um (quase) manual de ensino. Em Aberto, Brasília, v. 16, n. 69, p. 40-49, 1996.

LOGUERCIO, R. Q.; SAMRSLA, V. E. E.; DEL PINO, J. C. A dinâmica analisar livros didáticos com os professores de química. Química Nova, São Paulo, v. 24, n. 4, p. 557-562, 2001. 
LOPES, J. B.; BRANCO, J.; JIMENEZ-ALEIXANDRE, M. P. “Learning experience” provided by science teaching practice in a classroom and the development of students' competences. Research in Science Education, Dordrecht, v. 41, n. 5, p. 787-809, 2011.

LOPES, J. B.; VIEGAS, C.; CRAVINO, J. P. Improving the learning of physics and development of competences in engineering students. The International Journal of Engineering Education, Dublin, v. 26, n. 3, p. 612-627, 2010.

LOPES, J. B. et al. Constructing and using multimodal narratives to research in science education: contributions based on practical classroom. Research in Science Education, Dordrecht, v. 44, n. 3, p. 415-438, 2014.

Investigação sobre a mediação de professores de ciências físicas em sala de aula. Vila Real: Universidade de Trás-os-Montes e Alto Douro, 2010. Disponível em: <http:/ /www.ie.ul.pt/pls/portal/docs/1/301955.PDF>. Acesso em: 28 jan. 2015.

. Transversal traits in science education research relevant for teaching and research: a meta-interpretative study. Journal of Research in Science Teaching, Hoboken, v. 45, n. 5, p. 574-599, 2008.

MÉHEUT, M.; PSILLOS, D. Teaching-learning sequences: aims and tools for science education research. International Journal of Science Education, Abingdon, v. 26, n.5, p. 515-535, 2004.

MORTIMER, E. F.; MOL, G.; DUARTE, L. P. Regra do octeto e teoria da ligação química no ensino médio: dogma ou ciência? Química Nova, São Paulo, v. 17, n. 2, p.243-252, 1994.

PEREIRA JUNIOR, C. A.; AZEVEDO, N. R. Regra do octeto: obstáculo para aprendizado do conceito de ligações químicas. In: REUNIÃO ANUAL DA SOCIEDADE BRASILEIRA PARA O PROGRESSO DA CIÊENCIA, 63., 2011, Goiânia. Anais.... Goiânia: SBPC, 2011. Disponível em: < http://www.sbpcnet.org.br/livro/63ra/conpeex/prolicen/trabalhosprolicen/prolicen-carlos-antonio.pdf >. Acesso em: 20 nov. 2012.

PINTÓ, R.; COUSO, D.; GUTIERREZ, R. Using research on teachers' transformations of innovations to inform teacher education: the case of energy degradation. Science Education, Hoboken, v. 89, n. 1, p. 38-55, 2005.

PREDEBON, F.; DEL PINO, J. C. Uma análise evolutiva de modelos didáticos associados às concepções didáticas de futuros professores de química envolvidos em um processo de intervenção formativa. Investigações em Ensino de Ciências, Porto Alegre, v. 14, n. 2, p. 237-254, 2009. Disponível em: < http://www.if.ufrgs.br/ienci/artigos/Artigo_ID216/ v14_n2_a2009.pdf>. Acesso em: 28 jan. 2015.

ROEHRIG, G. H.; KRUSE, R. A.; KEM, A. Teacher and school characteristics and their influence on curriculum implementation. Journal of Research in Science Teaching, Hoboken, v. 44, n. 7, p. 883-907, 2007.

SÃO PAULO (Estado) Secretaria da Educação. Caderno do professor: química, ensino médio - 2a série. São Paulo, 2009. v. 2. 
SÃO PAULO (Estado) Secretaria da Educação. Proposta curricular do estado de São Paulo: química. São Paulo: SEE, 2008.

São Paulo faz escola. São Paulo, 2007. Disponível em: < http://www.rededosaber. sp.gov.br/portais/Home/tabid/1022/Default.aspx>. Acesso em: 02 fev. 2015.

TARDIF, M. Saberes docentes e formação profissional. Petrópolis: Vozes, 2002.

TRAIANOU, A.; HAMMERSLEY, M. Making science education evidence-based?: reflections on a Teaching and Learning Research Programme (TLRP) study. Oxford Review of Education, Abingdon, v. 34, n. 4, p. 461-481, 2008.

ZIMMERMANN, E.; BERTANI, J. A. Um novo olhar sobre os cursos de formação de professores. Caderno Brasileiro de Ensino de Física, Florianópolis, v. 20, n. 1, p. 43-62, 2003. Disponível em: <https://periodicos.ufsc.br/index.php/fisica/article/view/6563>. Acesso em: 28 jan. 2015. 